\title{
Targeted outreach hepatitis B vaccination program in high-risk adults: The fundamental challenge of the last mile
}

\section{M.-J.J. Mangen ${ }^{\mathrm{a}, \mathrm{b}, *}$, H. Stibbe ${ }^{\mathrm{b}, 1}$, A. Urbanus ${ }^{\mathrm{a}}$, E.C. Siedenburg ${ }^{\mathrm{c}}$, Q. Waldhober ${ }^{\mathrm{d}}$, G.A. de Wit ${ }^{\mathrm{b}, \mathrm{e}}$, J.E. van Steenbergen ${ }^{\mathrm{a}, \mathrm{f}}$, on behalf of the National Working Group of hepatitis B behavioural risk-groups vaccination program}

${ }^{a}$ Centre for Infectious Disease Control, National Institute for Public Health and the Environment, Bilthoven, The Netherlands

${ }^{b}$ University Medical Center Utrecht, Julius Center for Health Sciences and Primary Care, Utrecht, The Netherlands

${ }^{\mathrm{c}}$ Public Health Service Amsterdam, Amsterdam, The Netherlands

${ }^{\mathrm{d}}$ Netherlands Association of Community Health Services, Utrecht, The Netherlands

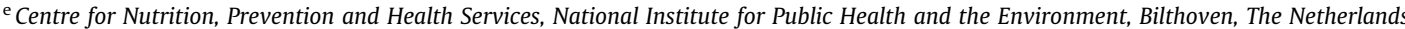

${ }^{\mathrm{f}}$ Centre of Infectious Diseases, Leiden University Medical Center, Leiden, The Netherlands

\section{A R T I C L E I N F O}

\section{Article history:}

Received 21 July 2016

Received in revised form 21 April 2017

Accepted 24 April 2017

Available online 5 May 2017

\section{Keywords:}

Hepatitis B virus vaccination

High-risk group

Men having sex with men

Commercial sex workers

Hard drug users

Cost-effectiveness

Economic evaluation

\begin{abstract}
A B S T R A C T
Background: The aim of this study was to evaluate the cost-effectiveness of the on-going decentralised targeted hepatitis B vaccination program for behavioural high-risk groups operated by regional public health services in the Netherlands since 1-November-2002. Target groups for free vaccination are men having sex with men (MSM), commercial sex workers (CSW) and hard drug users (HDU). Heterosexuals with a high partner change rate (HRP) were included until 1-November-2007.

Methods: Based on participant, vaccination and serology data collected up to 31-December-2012, the number of participants and program costs were estimated. Observed anti-HBc prevalence was used to estimate the probability of susceptible individuals per risk-group to become infected with hepatitis $\mathrm{B}$ virus (HBV) in their remaining life. We distinguished two time-periods: 2002-2006 and 2007-2012, representing different recruitment strategies and target groups. Correcting for observed vaccination compliance, the number of future HBV-infections avoided was estimated per risk-group. By combining these numbers with estimates of life-years lost, quality-of-life losses and healthcare costs of HBV-infections - as obtained from a Markov model-, the benefit of the program was estimated for each risk-group separately.

Results: The overall incremental cost-effectiveness ratio of the program was $€ 30,400 / Q A L Y$ gained, with effects and costs discounted at $1.5 \%$ and $4 \%$, respectively. The program was more cost-effective in the first period ( $€ 24,200 / \mathrm{Q} A \mathrm{~L})$ than in the second period ( $€ 42,400 / \mathrm{Q} A \mathrm{LY})$. In particular, the cost-effectiveness for MSM decreased from $€ 20,700 /$ QALY to $€ 47,700 / Q A L Y$.

Discussion and conclusion: This decentralised targeted HBV-vaccination program is a cost-effective intervention in certain unvaccinated high-risk adults. Saturation within the risk-groups, participation of individuals with less risky behaviour, and increased recruitment investments in the second period made the program less cost-effective over time. The project should therefore discus how to reduce costs per riskgroup, increase effects or when to integrate the vaccination in regular healthcare.
\end{abstract}

(c) 2017 Elsevier Ltd. All rights reserved.

\footnotetext{
Abbreviations: anti-HBc, hepatitis B core antigen; CSW, commercial sex workers; HBsAg, hepatitis B surface antigen; HBV, hepatitis B virus; HDU, hard drug users; HRP, heterosexuals with a high partner change rate; ICER, incremental costeffectiveness ratio; LYG, life years gained; MSM, men having sex with men; NIP, national universal childhood immunisation program; QALY, quality-adjusted life year; STI, sexual-transmittable infections; VE, vaccine effectiveness.

* Corresponding author at: Centre for Infectious Disease Control, National Institute for Public Health and the Environment (RIVM), PB Box 1 (within RIVM pb 75), 3720 BA Bilthoven, The Netherlands.

E-mail address: marie-josee.mangen@rivm.nl (M.-J.J. Mangen).

1 Present address: IGES Institute, Berlin, Germany.
}

\section{Introduction}

With some 248 million people having a chronic hepatitis-B virus (HBV) infection [1] chronic HBV is a major cause of morbidity and mortality worldwide. However, regional prevalence of HBV is highly variable [1] and the Netherlands is a low endemic country, with an estimated incidence of 1.2 acute HBV-infections/100,000 inhabitants in 2010 [2], and 0.2 percent of the population having chronic HBV-infections [3]. 
By the early nineties, the majority of European countries had incorporated HBV-vaccination in their national immunisation program (NIP) [4]. In the Netherlands this was found to be not costeffective due to the very low HBV-carrier prevalence and the relative high percentage of imported HBV-infections [5,6]. Introduction was therefore postponed until 2011 [7]. However, diverse risk-group oriented vaccinations programs were implemented, targeted at newborns of infected mothers (1989), occupational riskgroups (1999) and newborns with one or two parents originating from medium or high HBV-prevalence region (2003) [4]. Since November 2002, after a pilot [8], a national decentralised outreach program targeting high-risk adults was implemented. This program was targeted at: men having sex with men (MSM), harddrug users (HDU), including non-intravenous hard-drug use, commercial sex-workers (CSW), and female bisexuals and heterosexual individuals with a high rate of partner change (HRP) [9]. A first evaluation of the initial program (i.e. 2002-2006) considered both direct and indirect effects of the program and showed that the program overall was effective and cost-effective [10,11]. However, that approach did not allow an economic evaluation at riskgroup level, which is the focus of the current study.

The aim of the current study was to estimate the costeffectiveness of the targeted HBV-vaccination program for behavioural high-risk adults, both at program and at risk-group level, using a healthcare perspective. The program was evaluated for two separate time-periods (2002-2006 vs 2007-2012) and for the whole period.

\section{Methods}

\subsection{The vaccination program}

The risk-group vaccination program started 01.11.2002 and is ongoing. It is a national decentralised outreach program, operated by Regional/Public Health Services and coordinated from 2002 to 2008 by the Netherlands Association of Community Health Services, and since 2009 by the National Institute of Public Health and the Environment, in collaboration with the Netherlands Foundation for sexually transmitted infection and AIDS prevention, the Netherlands Institute of Mental Health and Addiction and the Foundation to promote Gay and Lesbian Sexual Health. The targeted 'classical' risk-groups were: (1) MSM; (2) CSW; (3) HDU and (4) HRP [12]. In November 2007, a major program change occurred, consisting of the exclusion of HRPs and the allocation of more money to improve recruitment strategies directed at younger MSMs [13]. By end 2011, vaccination of HDUs was transferred to the regular harm reduction programmes directed at these groups [14]. In this study we evaluated the program for 20022012.

Potential participants were recruited at a large variety of outreach locations and at usual healthcare facilities, such as Public Health Services, STI clinics or prison healthcare units [12,13,15]. At recruitment (i.e. first contact moment), all participants received the first vaccination and simultaneously a blood sample was collected for HBV-serology. Samples were tested for hepatitis B core antigen (anti-HBc) and, if positive, also for hepatitis B surface antigen (HBsAg). Participants negative for anti-HBc were considered susceptible for HBV-infection. Those testing anti-HBc positive but $\mathrm{HBsAg}$ negative were considered immune. When both anti-HBc and HBsAg were positive this indicated a chronic infection. Serological results were used in the second visit to decide for continuation of the vaccine series (in those without markers of previous infection), refer to regular health care for follow up (for those with chronic infection), or exclusion of the program (for those immune).
Susceptibles received a second and third vaccination 1 and 6 months after enrolment.

\subsection{Data collection}

Recruiting Health Services entered participant and vaccination data in a national web-based database. For the current study, we extracted and analysed data of participants having received their first vaccination between 1st-November-2002 and 31stDecember-2012. Information collected at recruitment included: birth date, gender, nationality, ethnic origin, sexual preference, working as CSW, using drugs, and date and location of first vaccination. Also, serology results and date of second and third vaccination were entered in the database.

\subsection{Risk-group assignment}

The risk-group was determined for each participant based on following criteria: (1) sexual preference; (2) gender; (3) working as CSW; (4) drug use; (5) and in case persons fell into more than one of the risk-groups, the location of the first vaccination determined the primary risk-group (supplemental Section 1).

Cases that could not be attributed to one of the four risk-groups were distributed over the four risk-groups in accordance to observed proportion of the different risk-groups in the year of recruitment (supplemental Section 1).

\subsection{Compliance}

Age- and risk-specific compliance was based on observed compliance of participants having had their first-time vaccination between 01.11.2002 and 31.12.2006 for the first time-period, and 01.01.2007 and 31.12.2010 for the second time-period, respectively (Table 1, supplemental Fig. S.1).

\subsection{Estimating the number of avoided hepatitis B infections}

Risk-group and time-group specific observed prevalence of anti-HBc was the starting point for estimating the risk of infection. The observed age-dependent cumulative anti-HBc prevalence curves for risk-group $r$ ( $r$ stands for MSM, CSW, HRP and HDU) and time-period $t$ ( $t$ stands for $t_{1}$ being period: 2002-2006 and $t_{2}$ being period: 2007-2012), as depicted in Fig. 1, were reversed in order to obtain age-dependent lifetime risk of an infection for susceptible participants of risk-group $r$ and time period $t$. We assumed that susceptible participants of risk-group $r$ in period $t$ would show similar risk behaviour through their life as their already infected peers. Taking into account the age at first vaccination of susceptible individuals in risk-group $r$ and in time-period $t$, we estimated for all susceptible individuals in age-class $a$ of risk-group $r$ the number of expected infections over their remaining life time until the age of 60 years, assuming that no vaccination would have taken place. We repeated this analysis for a situation with sub-optimal compliance to vaccination, based on observed uptake of one, two and three vaccine doses (Table 1). Based on Williams et al. [16], we assumed vaccine effectiveness (VE) of $90 \%, 70 \%$ and $40 \%$ for three, two and one vaccine dose, respectively. Furthermore, we assumed that protection would last life-long $[16,17]$. The difference between the two scenarios serves as our estimate of then the number of avoided hepatitis B infections.

\subsection{Vaccination program costs}

Program costs were composed of: (1) variable costs such as vaccine costs, laboratory testing and consultations; (2) outreach activities consisting of costs for material and staff (including planning); 
Table 1

Baseline characteristics.

\begin{tabular}{|c|c|c|c|c|c|c|c|c|}
\hline & \multicolumn{2}{|l|}{ MSM } & \multicolumn{2}{|l|}{ CSW } & \multicolumn{2}{|l|}{ HDU } & \multicolumn{2}{|l|}{ HRP } \\
\hline & $\begin{array}{l}2002- \\
2006\end{array}$ & $\begin{array}{l}2007- \\
2012\end{array}$ & $\begin{array}{l}2002- \\
2006\end{array}$ & $\begin{array}{l}2007- \\
2012\end{array}$ & $\begin{array}{l}2002- \\
2006\end{array}$ & $\begin{array}{l}2007- \\
2012\end{array}$ & $\begin{array}{l}2002- \\
2006\end{array}$ & $\begin{array}{l}2007- \\
2012\end{array}$ \\
\hline Number of participants & $15,335^{a}$ & $23,576^{a}$ & $8661^{\mathrm{a}}$ & $8985^{\mathrm{a}}$ & $11,471^{\mathrm{a}}$ & $7117^{\mathrm{a}}$ & $30,223^{a}$ & $13,241^{\mathrm{a}}$ \\
\hline Male (in\%) & $100.0 \%$ & $99.5 \%$ & $16.1 \%$ & $14.4 \%$ & $82.2 \%$ & $81.6 \%$ & $52.3 \%$ & $56.3 \%$ \\
\hline Dutch nationality (in\%) ${ }^{\mathrm{b}}$ & $85.0 \%$ & $81.8 \%$ & $48.0 \%$ & $41.5 \%$ & $73.8 \%$ & $69.8 \%$ & $75.3 \%$ & $72.5 \%$ \\
\hline Mean (median) age in years ${ }^{\mathrm{b}}$ & $32.8(31.0)$ & $32.8(31.0)$ & $32.8(31.0)$ & $32.8(31.0)$ & $32.8(31.0)$ & $32.6(31.0)$ & $32.8(31.0)$ & $33.0(31.0)$ \\
\hline anti-HBc- (i.e. susceptible) ${ }^{\mathrm{b}}$ & $85.2 \%$ & $91.5 \%$ & $83.7 \%$ & $87.3 \%$ & $83.0 \%$ & $90.6 \%$ & $94.4 \%$ & $95.3 \%$ \\
\hline anti-HBc+ (i.e. immune $)^{\mathrm{b}}$ & $14.7 \%$ & $8.2 \%$ & $16.0 \%$ & $12.4 \%$ & $16.7 \%$ & $9.1 \%$ & $5.5 \%$ & $4.5 \%$ \\
\hline Carrier rate $\mathrm{HBsAg}+/ \mathrm{antiHBc}+(\mathrm{in} \%)$ of infected cases ${ }^{\mathrm{b}}$ & $5.7 \%$ & $5.8 \%$ & $6.6 \%$ & $8.2 \%$ & $4.9 \%$ & $7.4 \%$ & $10.2 \%$ & $12.1 \%$ \\
\hline Susceptible obtaining 2 nd vaccination ${ }^{\mathrm{b}}$ & $91.4 \%$ & $87.3 \%$ & $80.9 \%$ & $76.5 \%$ & $89.0 \%$ & $80.3 \%$ & $82.4 \%$ & $80.3 \%$ \\
\hline Susceptible obtaining 3rd vaccination ${ }^{\mathrm{b}}$ & $80.9 \%$ & $73.7 \%$ & $56.6 \%$ & $51.1 \%$ & $66.9 \%$ & $52.1 \%$ & $65.2 \%$ & $52.1 \%$ \\
\hline
\end{tabular}

Abbreviations used: MSM: men having sex with men; HRP: heterosexuals with a high rate of partner change; CSW: commercial sex workers; HDU: hard drug users.

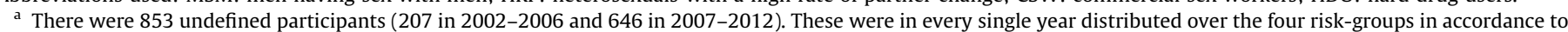


90 in $t_{2}$ ); and 225 to HRP (98 in $t_{1}$ and 127 in $t_{2}$ ); see also supplemental Section 1.

b As observed within the risk-group, excluding undefined cases.

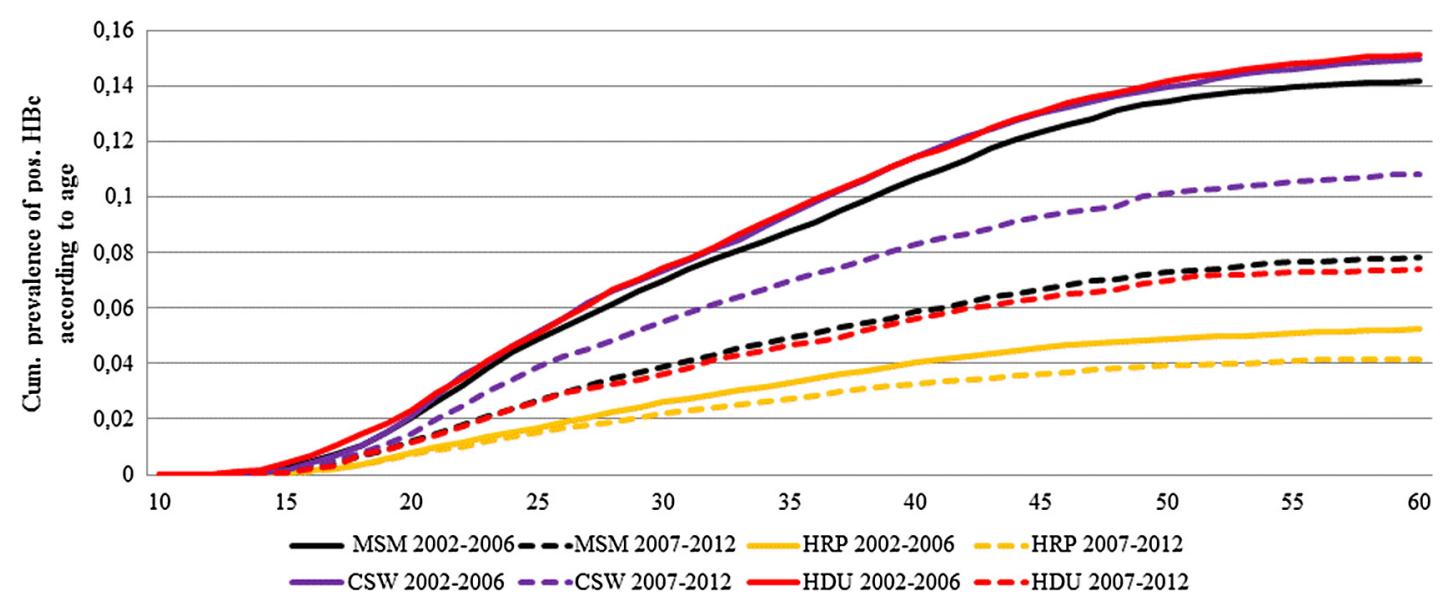

Fig. 1. Age-dependent cumulative anti-HBc prevalence curves by risk-group and time-period.

(3) information material consisting of flyers, banners at websites and the creation of specific websites [15]; and (4) overhead costs such as national coordination and building and maintenance costs for database and websites. Variable costs consisted of (i) material costs (e.g. vaccine), and (ii) staff costs based on a detailed analysis of activities in the pilot-project [8]. These were estimated based on the number of participants reached in risk-group $r$ in time-period $t$. All other cost details were obtained from the coordinating offices. The costs were expressed in 2012 euros, using Dutch consumer price indexes. Direct costs, outreach activities and information material were labelled and could be allocated to the corresponding risk-group. For the overhead costs, we assumed a proportional distribution over the four risk-groups according to the number of estimated participants in each risk-group. Potential side-effects of vaccination were considered to be marginal and therefore neglected in the current study as was also done by other HBV vaccine modellers (e.g. [18-20]).

\subsection{Estimating quality-adjusted life years, life-years lost and healthcare costs}

Estimating cost-effectiveness requires evidence on the life-long consequences of infection, e.g. with regard to mortality, morbidity and healthcare costs. For 5-year age groups, we used estimates from a Markov-chain disease model on the age-dependent lifeyears lost due to HBV-infection, number of quality-adjusted-lifeyears (QALYs) lost due to HBV-infection, and life-time healthcare costs. These estimates are summarized in supplemental Table S.6. This Markov model [6] was updated to represent current medical practice (details in supplemental Section 3).

By adding-up the estimated number of avoided infections over all susceptible individuals in risk-group $r$ and in time-period $t$, while considering risk- and age-dependent probabilities for compliance, we estimated the number of QALYs gained, life years gained (LYG) and the healthcare costs avoided because of the program in risk-group $r$ in time-period $t$. Discounting was applied according to Dutch guidelines, i.e. $1.5 \%$ for effects and $4 \%$ for costs [21].

\subsection{Cost-effectiveness analysis}

The cost-effectiveness model was implemented in Microsoft Excel. Costs and effects at the level of the vaccinated individuals were considered until the age of 60 years. Susceptible persons that were $\geq 60$ years were excluded as most of these persons, if chronically infected at an age over 60, would not develop chronic complications before death. Net costs per risk-group $r$ for time-period $t$ were obtained by subtracting the estimated healthcare savings for risk-group $r$ and time-period $t$ from the vaccination costs for risk-group $r$ and time-period $t$. Incremental cost-effectiveness ratios (ICER) were estimated, relating the net costs to different effects: (1) persons reached; (2) infection avoided; (3) QALYs gained and (4) life years gained. 


\subsection{Sensitivity and scenario analyses}

Univariate sensitivity analyses was conducted. For international comparison, different discount rates for costs and effects were applied. Assumed life-time risk was decreased/increased by $10 \%$. Assumed constant VE was decreased/increased by 5\%. Agedependent VE rather than constant VE was modelled using the estimated three-dose VE of Vermeiren et al. [22]. For the secondand one-dose VE, the same age-dependent curve was followed, but assuming, based on Williams [20], that VE would be $30 \%$ and $50 \%$, respectively lower than the three-dose VE (supplemental Fig. S.4). As a scenario analysis we further assumed that all participants would have been vaccinated at young age, i.e. seventeen years at first-vaccination - an unattained objective in $t_{2}$.

\section{Results}

A total of 118,609 participants were reached between 1 stNovember-2002 and 31th-December-2012, whereof 32.8\%, 14.9\%, $15.7 \%$ and $36.6 \%$ being classified as MSMs, CSWs, HDUs and HRPs, respectively. Distinguishing the two periods, 55\% was reached between 2002 and 2006 and 45\% between 2007 and 2012 (Table 1, Supplemental Fig. S.5).

Overall, 853 cases could not be attributed to one of the four risk-groups. They were distributed/year over the four risk-groups in accordance to observed proportion of the different risk-groups in the year of recruitment (supplemental Section 1).The average age of all participants was 32.8 years (median $=31$ ). There was no significant difference in age between risk-groups or between time-periods (Table 1 ). The percentage of susceptibles reached varied between $83.0 \%$ for HDU in $t_{1}$ and $95.3 \%$ for HRP in $t_{2}$ (Table 1 ), and was slightly higher in all four risk-groups in $t_{2}$. Compliance varied between risk-groups and time-periods. In $t_{1}, 80.9 \%$ of MSM finished the complete vaccination schedules versus 51.1\% of CSW in $t_{2}$ (Table 1 ). Compliance was slightly lower in $t_{2}$.

The vaccination program costed $€ 23.4$ million ( $€ 19.5$ million, if discounted at $4 \%$ ), with $€ 11.5$ million and $€ 11.9$ million spend in $t_{1}$ and $t_{2}$, respectively. During the whole period were $44 \%, 14 \%, 18 \%$ and $24 \%$ of the program costs made to reach MSM, CSW, HDU and HRP, respectively (Fig. 2).

The whole vaccination program from 2002 to 2012 was estimated to result in 4285 avoided infections (3.6/100 participants), resulting in $€ 1.55$ million saved lifetime costs, 592 QALYs gained and 350 LYG (Table 2). More than $60 \%$ of the avoided infections would be realised in participants from $t_{1}$. With 4.9 avoided infections/100 participants reached, vaccinating CSW is most effective, while vaccinating HRPs, with 2.1 avoided infection/100 participants reached was least effective (Supplemental Table S.7).

The net-cost per person reached varied from $€ 83$ for HRPs in $t_{2}$ up to $€ 210$ for MSM in $t_{2}$ (Table 2 ). The program was more costeffective in $t_{1}$ than in $t_{2}$, independent of the outcome measure used, i.e. cost/avoided infection ( $€ 3480$ in $t_{1}$ versus $€ 5440$ in $t_{2}$ ), cost/QALY gained ( $€ 24,200$ in $t_{1}$ versus $€ 42,400$ in $t_{2}$ ), cost/LYG ( $€ 40,800$ in $t_{1}$ versus $€ 71,800$ in $t_{2}$ ), Table 2 and Fig. 3. Vaccination of HDU, CSW and MSM costed less than $€ 21,000 / \mathrm{QALY}$ in $t_{1}$, whereas for HRP this was $€ 35,900 / Q A L Y$. The program was less cost-effective in $t_{2}$, resulting in ICERs of $€ 25,800 / Q A L Y, € 47,700 /$ QALY and $€ 54,000 /$ QALY for CSW, MSM and HDU (Table 2 and Fig. 3).

Sensitivity analyses show that assumed lifetime risk and/or assumed VE had little impact on estimated ICERs (Fig. 4, supplemental Fig. S.6 and Fig. S.7). The most influential variable was the discount rate for health effects, using $4 \%$ rather than $1.5 \%$ would result in an ICER of the whole program of $€ 56,000 / Q A L Y$ versus $€ 30,400 / Q A L Y$. Vaccinating all participants at age seventeen would have been more cost-effective ( $€ 11,600 / \mathrm{Q} A L Y$ gained) than vaccination at higher age, as observed in this study.

\section{Discussion}

Only in 2011 was HBV included in the NIP, necessitating enhanced efforts to reach high-risk groups for vaccination. For behavioural risk-groups a decentralised outreach program was developed. In the current cost-effectiveness analysis (CEA) we show that the initial 4-year program $\left(t_{1}: 2002-2006\right)$ was reasonable cost-effective with an ICER of $€ 24,400 / Q A L Y$. The extension of the program $\left(t_{2}: 2007-2012\right)$ resulted in less favourable ICERs.

In $t_{1}$, vaccination of HDUs and CSWs was most (cost)-effective, despite their low compliance, and vaccination of HRP was found to be least (cost)-effective. The relatively favourable ICER of $€ 38,700 /$ QALY for HRP in $t_{2}$ is somewhat misleading. This program stopped in November 2007, meaning no expensive outreach activities, but only vaccination of HRPs in healthcare facilities during almost one year. CSW was the most (cost)-effective risk-group for vaccination in both time-periods. It is important to realize that over $50 \%$ of CSWs do not have Dutch citizenship. This group of CSWs, frequently originating from countries of high HBV endemicity, travels to The Netherlands on tourist visa and are working in this sector for three month time periods, travelling onwards for similar work in neighbouring countries, returning home periodically, and also re-entering the Netherlands to work in other cities. Consequently, the estimated benefits are not only gained in The Netherlands but also in their home country as well as other European countries, resulting in less favourable ICERs than presented. Vaccinations of CSWs originating from countries with high hepatitis B endemicity will have to be continued until also in those countries the vaccination coverage has included their age group. The cost-effectiveness for the MSM decreased dramatically from $€ 20,700 / Q A L Y$ gained in $t_{1}$ to $€ 47,700 /$ QALY gained in $t_{2}$. High investments made to (out-) reach younger MSMs did not pay off. The average age of MSM (32.8 years) was similar in both periods, despite all efforts to decrease the age of vaccination. Should participants indeed have been reached at a younger age, the program would have been far more cost-effective (Fig. 4). The challenge therefore is how to reach younger ages. The best solution for providing protection at an early age is universal childhood vaccination. HBV was introduced in 2011 in NIP, hence, it will need another two decades before this will have effect in reducing transmission in the high-risk groups. Vaccinations of CSWs originating from countries with high hepatitis B endemicity will have to be continued until also in those countries the vaccination coverage has included their age group. Another important finding is that in the second period the prevalence of hepatitis $B$ is lower in all high-risk groups. This might be interpreted as a sign that the Dutch and worldwide efforts to reduce transmission of the HBV are having some effect. This is in line with the observed decrease in number of notified acute infections [3]. Furthermore, other factors, such as saturation within the risk-groups [23], extension to lower risk behaviour and increased recruitment investments over time may have contributed to less favourable cost-effectiveness in $t_{2}$.

Anti-HBc prevalence is a driving variable in the study, and Fig. 1 shows that vaccination should take place early in life (before age 15) to optimally prevent hepatitis B infections. The problem of the whole program is that the participants are frankly spoken too old (average age was $\sim 33$ years). In case of hepatitis B vaccination it is crucial to vaccinate the young ones (which the program failed to do). The older you are at time of vaccination, the fewer complications to prevent, and therefore the fewer lifetime costs and QALY losses to prevent. Discounting further impacts these lifetime costs and QALY losses that might be prevented by an avoided infection. 


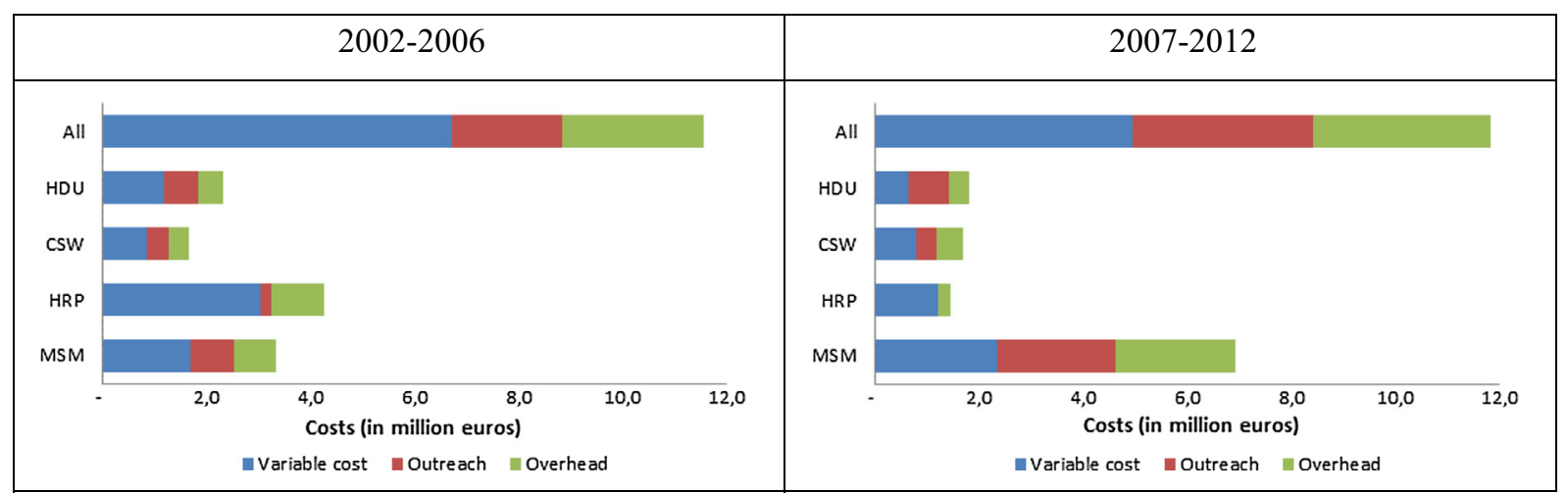

Fig. 2. Undiscounted vaccination program cost by risk-group, time-period and cost-category in 2012 euros.

Table 2

Main results for the whole program (i.e. all risk-groups together) and for each single risk-group for the two separate periods $\left(t_{1}=2002-2006\right.$ vs $\left.t_{2}=2007-2012\right)$.

\begin{tabular}{|c|c|c|c|c|c|c|c|c|c|c|}
\hline & \multicolumn{2}{|l|}{ MSM } & \multicolumn{2}{|l|}{ CSW } & \multicolumn{2}{|l|}{ HDU } & \multicolumn{2}{|l|}{ HRP } & \multicolumn{2}{|c|}{ Whole program } \\
\hline & $t_{1}$ & $t_{2}$ & $t_{1}$ & $t_{2}$ & $t_{1}$ & $t_{2}$ & $t_{1}$ & $t_{2}$ & $t_{1}$ & $t_{2}$ \\
\hline Number of persons reached & 15,335 & 23,576 & 8661 & 8985 & 11,471 & 7117 & 30,223 & 13,241 & 65,690 & 52,919 \\
\hline Program costs, in million $€(4 \%)$ & 3.07 & 5.20 & 1.53 & 1.24 & 2.13 & 1.40 & 3.81 & 1.17 & 10.54 & 9.00 \\
\hline Saved lifetime costs, in million $€(4 \%)$ & 0.36 & 0.25 & 0.18 & 0.11 & 0.26 & 0.06 & 0.27 & 0.07 & 1.07 & 0.49 \\
\hline Net costs, in million $€(4 \%)$ & 2.71 & 4.95 & 1.34 & 1.13 & 1.87 & 1.34 & 3.54 & 1.10 & 9.47 & 8.52 \\
\hline Number of infections avoided & 874 & 777 & 493 & 363 & 652 & 200 & 699 & 227 & 2718 & 1567 \\
\hline QALYs gained (1.5\%) & 131.4 & 103.8 & 67.4 & 43.9 & 93.6 & 24.7 & 98.8 & 28.3 & 391.1 & 200.7 \\
\hline YLLs gained $(1.5 \%)$ & 77.7 & 61.2 & 40.0 & 26.0 & 55.3 & 14.6 & 58.8 & 16.8 & 231.9 & 118.5 \\
\hline ICER: Costs/person reached ${ }^{\mathrm{a}}$ & 177 & 210 & 155 & 126 & 163 & 188 & 117 & 83 & 144 & 161 \\
\hline ICER: Costs/avoided infection ${ }^{a}$ & 3100 & 6400 & 2700 & 3100 & 2900 & 6700 & 5100 & 4800 & 3500 & 5400 \\
\hline ICER: Costs/QALY ${ }^{a}$ & 20,700 & 47,700 & 19,900 & 25,800 & 20,000 & 54.000 & 35,900 & 38,700 & 24,200 & 52,400 \\
\hline ICER: Costs/YLL ${ }^{\mathrm{a}}$ & 34,900 & 80,900 & 33,600 & 43,700 & 33,800 & 91,300 & 60,200 & 65,400 & 40,800 & 71,800 \\
\hline
\end{tabular}

${ }^{\text {a }}$ Results are rounded to 3-significant numbers.

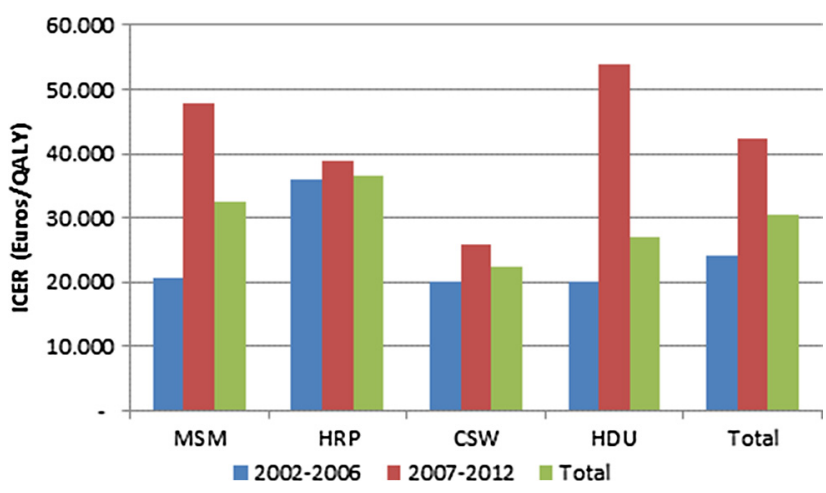

Fig. 3. Incremental cost-effectiveness ratios expressed as $€$ per QALY for the whole period (2002-2012) and for the two separated periods (2002-2006 vs 2007-2012), for the whole program (i.e. all risk-groups together) and for each single risk-group.

In MSMs, the anti-HBc prevalence decreased from $14.7 \%$ in $t_{1}$ to $8.2 \%$ in $t_{2}$. The prevalence in $t_{1}$ was similar to the $15.3 \%$ for British MSM recruited via outreach activities [24]. In HRPs, the anti-HBc prevalence was with $5.5 \%\left(t_{1}\right)$ and $4.5 \%\left(t_{2}\right)$, higher than the $0.8 \%$ $3.2 \%$ reported in heterosexual STI clinics visitors in other lowendemic countries $[25,26]$. This is in line with the high participation of "swingers" in the HRPs, of whom it is known that they have a high STI prevalence [27]. The anti-HBc prevalence found in CSWs is similar to what is found in neighbouring countries [28]. In HDUs, the anti-HBc prevalence was $16.7 \%\left(t_{1}\right)$ and $9.1 \%\left(t_{2}\right)$ respectively. This is lower than the $22.5 \%$ reported for injecting drug users and

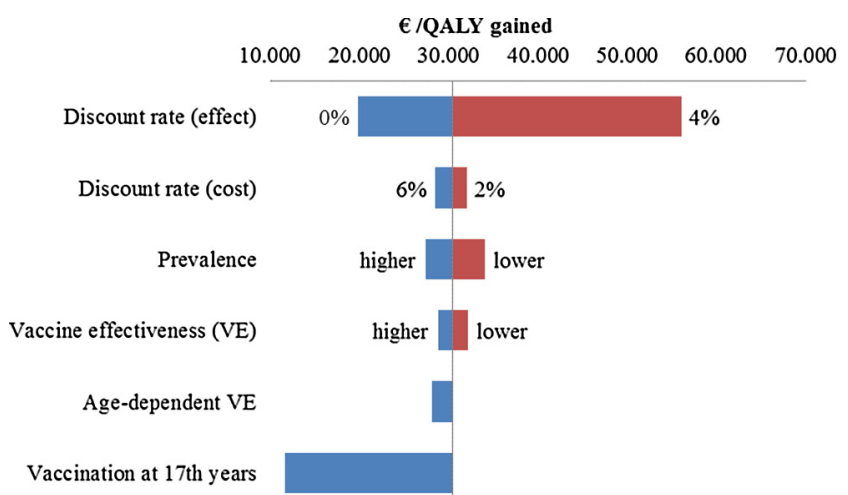

Fig. 4. Sensitivity and scenario analyses conducted for the whole vaccination program from 2002-2012.

higher than the $7.4 \%$ for non-injecting drug users in Spain [29]. The lower prevalence in $t_{2}$ is according to the observed trend of abstaining from injecting drug use [14].

To our knowledge, this study is the first to report costeffectiveness of risk-group vaccination at the level of different risk-groups. Other strengths of our study are the large number of participants and the long observation period. However, there are also some limitations. A major limitation of the current study is that we only considered direct benefits in participants, and omitted potential indirect benefits of avoided infections in third persons. Consequently, the actual cost-effectiveness of the program will 
be more favourable than currently estimated. With an estimated 4285 prevented infections, of which 2700 in the first 4-years, we differ from Kretzschmar et al. [10] who obtained, a total of 5700 (4,100-6900) prevented infections assuming that participants are in the two highest sexual-activity levels. However, they considered both direct and indirect benefits, whereas we estimated only the direct benefit. Also, it is unlikely that all vaccinated MSM belong to the two highest sexual-activity levels. Furthermore, by considering CSWs, HDUs and HRPs together with all other heterosexuals, their model was less suitable to account for particularities in lifestyle of the different risk-groups. Both our study and the Kretzschmar et al. study agree on the fact that a targeted catch-up vaccination might be effective in preventing HBV-infections. One final limitation is related to the fact that we did not adjust for background quality of life, implicitly assuming that quality of life of non-diseased populations is always 1 . Obviously, quality of life decreases with older age and correction for such sub-optimal quality of life would have limited the importance of prevention of HBV related disease states slightly, especially in older age-groups in which quality of life further deviates from 1 . However, this limitation adds to the conclusion that vaccination of older age groups is not cost-effective, even more so if less QALYs are to be gained by vaccination after correction for background quality of life.

By not testing for previous vaccination in non-Dutch citizens, the program may have wrongly classified them as being "susceptible". As a consequence, we may have overestimated the lifetime risk of infection and therefore the ICER. This holds in particular for CSWs, where the proportion of non-Dutch citizens was high. Furthermore, this high-risk adult population is expected to be more often infected with other sexually transmitted diseases with a considerable impact on both quality-of-life and longevity of individuals. Therefore, the average life expectancy for risk-groups as CSWs and HDUs might be lower than for the average Dutch population, as used for calculating LYG. Consequently, estimated healthcare savings, QALYs gained and LYG gained due to vaccination might be overestimated, causing an overestimation of costeffectiveness of the program. At the same time, the avoidance of a HBV-infection in persons with other sexually transmitted diseases (super-infections) might compensate part of this overestimation, because super-infections are associated with disproportional higher healthcare costs and premature death. A further limitation is the choice of treatment when estimating lifetime costs. In 2002, the starting year of the program, interferon was the recommended therapy for chronic hepatitis B-infections, and the underlying therapy in our study for estimating healthcare savings and QALYs gained. Progress in medicine has result in new, but more costly therapies (i.e., higher lifetime costs to prevent), but with fewer side-effects (i.e., fewer QALYs to gain when preventing infection). Our ICERs therefore may be regarded as conservative estimates.

We conclude that this targeted HBV-vaccination program is a cost-effective intervention in certain unvaccinated high-risk adults, and was a good alternative to NIP. In the Netherlands, HBV vaccination was only introduced in the NIP in 2011. In order to have prevented HBV transmission in adult populations as of 2002, HBV vaccination should have been introduced in the NIP at the earliest availability of the HBV vaccine in the 1980s. At that time, vaccine costs were far higher and introduction of HBV vaccine in the NIP was deemed not cost-effective (i.e. $€ 57,600 /$ life year gained [6]). However, over the time the adult risk-group vaccination program became less cost-effective, while the NIP became more cost-effective due to decreasing vaccine cost. The challenge for the future is to reach the "last mile" in a cost-effective way up to that date that the majority of persons will be protected via NIP. It should therefore be discussed how to reduce costs per risk-group, increase effects or when to integrate the vaccination in regular healthcare i.e. during regular consultations with the GP, STI clinics or Public Health Services.

\section{Author's contributions}

All authors contributed significantly to the work of this manuscript. MJJM and JvS conceived the study. MJJM, HS and GAdW developed the models. MJJM and HS conducted the analysis. MJJM wrote the manuscript. HS, AU, QW, ES, GAdW and JvS critically revising the manuscript. All authors read and approved the final manuscript.

\section{Funding}

The pilot study was, and the subsequent program is funded by the Ministry of Health, Welfare and Sport.

\section{Conflict of interest}

MJJM, HS, AU, ES,QW GAdW and JvS have no conflict of interest.

\section{Acknowledgments}

We would like to thank all recent and past members from the National Working Group of hepatitis B behavioural risk-groups vaccination program, in particular Laura Rust (GGD GHOR Nederland), Paul Zantkuijl (Soa Aids Nederland), Thirza Stewart (Soa Aids Nederland) and Christian Hoebe (GGD Zuid Limburg). We further would like to thank all local teams of the Regional/Public Health Services and of the STI clinics for their valuable work in the recruitment of participants. All participants are acknowledged for their participation in the program. Paul van Beek (RIVM) is acknowledged for help with determining the program costs. Mirjam Kretzschmar (RIVM), Marie-Louise Heijnen (RIVM) and Irene Veldhuijzen (RIVM) are acknowledged for critical feedback on previous drafts.

\section{Appendix A. Supplementary material}

Supplementary data associated with this article can be found, in the online version, at http://dx.doi.org/10.1016/j.vaccine.2017.04. 068 .

\section{References}

[1] Schweitzer A, Horn J, Mikolajczyk RT, Krause G, Ott JJ. Estimations of worldwide prevalence of chronic hepatitis B virus infection: a systematic review of data published between 1965 and 2013. Lancet 2015;386 (10003):1546-55.

[2] Hahne S, van Houdt R, Koedijk F, van Ballegooijen M, Cremer J, Bruisten S, et al. Selective hepatitis B virus vaccination has reduced hepatitis B virus transmission in the Netherlands. PLoS ONE 2013;8(7):e67866.

[3] Hahne SJ, De Melker HE, Kretzschmar M, Mollema L, Van Der Klis FR, Van Der Sande MA, et al. Prevalence of hepatitis B virus infection in The Netherlands in 1996 and 2007. Epidemiol Infect 2012;140(8):1469-80.

[4] Mereckiene J, Cotter S, Lopalco P, D’Ancona F, Levy-Bruhl D, Giambi C, et al. Hepatitis B immunisation programmes in European Union, Norway and Iceland: where we were in 2009? Vaccine 2010;28(28):4470-7.

[5] Kretzschmar M, de Wit GA, Smits LJ, van de Laar MJ. Vaccination against hepatitis B in low endemic countries. Epidemiol Infect 2002;128(2):229-44.

[6] De Wit GA, Kretzschmar MEE, Smits LJM, Struijs JN, Postma MJ, van der Laar MJW, Jager JC. Kosten-effectiviteit van algemene vaccinatie tegen hepatitis B: interim rapport [Cost effectiveness of national hepatitis B vaccination: interim report]. (In Dutch). Bilthoven: National Institute for Publich Health, 2000. RIVM Rapport 403505004. Available at: <http://www.rivm.nl/bibliotheek/ rapporten/403505004.pdf>.

[7] Health council of the netherlands. general vaccination against hepatitis B revisited. The hague: health council of the netherlands, 2009 Contract No. Report No.: 2009/03E. Available at: <https://www.gezondheidsraad.nl/sites/ default/files/200903_0.pdf>. 
[8] van Steenbergen JE. Working group vaccination high-risk groups hepatitis B for the Netherlands. Results of an enhanced-outreach programme of hepatitis B vaccination in the Netherlands (1998-2000) among men who have sex with men, hard drug users, sex workers and heterosexual persons with multiple partners. J Hepatol 2002;37(4):507-13.

[9] Laluan E, van de Mheen D. Klassieke Risicogroepen Hepatitis B Omvangschattingen van Homoseksuele mannen, Prostitué(e)s, Druggebruikers en Bezoekers van SOA-poliklinieken. Rotterdam: Instituut voor Onderzoek naar Leefwijzen \& Verslaving; 2002.

[10] Kretzschmar M, Mangen MJJ, van de Laar M, de Wit GA. Model based analysis of hepatitis B vaccination strategies in the Netherlands. Vaccine 2009;27 (8):1254-60.

[11] de Wit GA, Kretzschmar M, Mangen MJJ. Is de vaccinatie van risicogroepen tegen hepatitis B kosten-effectief? Nederlands congres Volksgezondheid 2006; 12-13 april 2006. De Doelen, Rotterdam.

[12] Waldhober Q, Heijnen M-L. Landelijke bereik van HBV-vaccinatiecampagne risicogroepen. Infectieziekte Bull 2003;14(7):249-53.

[13] Heijnen M-L, Meerburg BG, Waldhober Q de Vries M, Hahné S. Landelijke hepatitis B-vaccinatiecampagne voor gedragsgebonden risicogroepen: resultaten en veranderingen. Infectieziekten Bull 2007;18(11):380-3.

[14] van Dam M, van Ouwerkerk IMS, van den Kerkhof JHTC, Timen A. Vaccinatieprogramma hepatitis B-risicogroepen: harddruggebruikers vanaf 2012 geen risicogroep meer. Infectieziekte Bull 2011;22(9):335-8.

[15] Rodenburg A, Waldhober Q, van Wijngaarden I. Van nieuw project tot geintegreerd werk - Lessen uit 6 jaar hepatitis B vaccinatiecampagne. Utrecht: GGD Nederland, 2009 Contract No.: GGD Nederland 2009/27.

[16] Mossner BK, Skamling M, Jorgensen TR, Georgsen J, Pedersen C, Christensen PB. Decline in hepatitis B infection observed after 11 years of regional vaccination among Danish drug users. J Med Virol 2010;82(10):1635-9.

[17] Lugoboni F, Migliozzi S, Mezzelani P, Pajusco B, Ceravolo R, Quaglio G. Progressive decrease of hepatitis B in a cohort of drug users followed over a period of 15 years: the impact of anti-HBV vaccination. Scand J Infect Dis 2004;36(2):131-3.

[18] Rossi C, Schwartzman K, Oxlade O, Klein MB, Greenaway C. Hepatitis B screening and vaccination strategies for newly arrived adult Canadian immigrants and refugees: a cost-effectiveness analysis. PLoS ONE 2013;8 (10):e78548.
[19] Kuan RK, Janssen R, Heyward W, Bennett S, Nordyke R. Cost-effectiveness of hepatitis B vaccination using HEPLISAV in selected adult populations compared to Engerix-B(R) vaccine. Vaccine 2013;31(37):4024-32.

[20] Williams JR, Nokes DJ, Medley GF, Anderson RM. The transmission dynamics of hepatitis B in the UK: a mathematical model for evaluating costs and effectiveness of immunization programmes. Epidemiol Infect 1996;116 (1):71-89.

[21] Tan SS, Bouwmans CA, Rutten FF, Hakkaart-van Roijen L. Update of the dutch manual for costing in economic evaluations. Int J Technol Assess Health Care 2012;28(2):152-8.

[22] Vermeiren AP, Hoebe CJ, Dukers-Muijrers NH. High non-responsiveness of males and the elderly to standard hepatitis B vaccination among a large cohort of healthy employees. J clin virol: off publ Pan Am Soc for Clin Virol 2013;58 (1):262-4.

[23] van Rijckevorsel G, Whelan J, Kretzschmar M, Siedenburg E, Sonder G, Geskus $\mathrm{R}$, et al. Targeted vaccination programme successful in reducing acute hepatitis B in men having sex with men in Amsterdam, the Netherlands. J Hepatol 2013;59(6):1177-83.

[24] Warwick Z, Dean G, Carter P. B safe, B sorted: results of a hepatitis B vaccination outreach programme. Int J STD AIDS 2007;18(5):335-7.

[25] Stenkvist J, Lidbrink P, Olofsson I, von Sydow M, Lindh G. Hepatitis B seroprevalence in persons attending youth clinics in Stockholm, Sweden in 2008. Int J STD AIDS 2012;23(11):767-71.

[26] el-Dalil AA, Jayaweera DT, Walzman M, Radcliffe KW, Richmond R, Wade AA, et al. Hepatitis B markers in heterosexual patients attending two genitourinary medicine clinics in the West Midlands. Genitourin Med 1997:73(2):127-30.

[27] Dukers-Muijrers NH, Niekamp AM, Brouwers EE, Hoebe CJ. Older and swinging; need to identify hidden and emerging risk groups at STI clinics. Sex Transm Infect 2010;86(4):315-7.

[28] Mak R, Traen A, Claeyssens M, Van Renterghem L, Leroux-Roels G, Van Damme P. Hepatitis B vaccination for sex workers: do outreach programmes perform better? Sex Transm Infect 2003;79(2):157-9.

[29] Vallejo F, Toro C, de la Fuente L, Brugal MT, Soriano V, Silva TC, et al. Prevalence of and risk factors for hepatitis B virus infection among street-recruited young injection and non-injection heroin users in Barcelona, Madrid and Seville. Eur Addict Res 2008;14(3):116-24. 